Article

\title{
Spark Plasma Sintering Apparatus Used for High-temperature Compressive Creep Tests
}

\author{
Barak Ratzker, Sergey Kalabukhov and Nachum Frage * \\ Department of Materials Engineering, Ben-Gurion University of the Negev, P.O.B. 653, Beer-Sheva 84105, Israel; \\ ratzkerb@post.bgu.ac.il (B.R.); kalabukh@bgu.ac.il (S.K.) \\ * Correspondence: nfrage@bgu.ac.il; Tel.: +972-8-646-1468; Fax: +972-8-647-9441
}

Received: 10 November 2019; Accepted: 13 January 2020; Published: 15 January 2020

\begin{abstract}
Creep is a time dependent, temperature-sensitive mechanical response of a material in the form of continuous deformation under constant load or stress. To study the creep properties of a given material, the load/stress and temperature must be controlled while measuring strain over time. The present study describes how a spark plasma sintering (SPS) apparatus can be used as a precise tool for measuring compressive creep of materials. Several examples for using the SPS apparatus for high-temperature compressive creep studies of metals and ceramics under a constant load are discussed. Experimental results are in a good agreement with data reported in literature, which verifies that the SPS apparatus can serve as a tool for measuring compressive creep strain of materials.
\end{abstract}

Keywords: spark plasma sintering apparatus; compressive creep test; stress exponent; electric current

\section{Introduction}

Creep is the continuous deformation of a material subjected to a constant load or stress, often lower than its yield strength. It is a process that is very sensitive to temperature, generally considered as high-temperature deformation, which occurs at roughly $\geq 0.5 T / T_{m}$ (where $T / T_{m}$ in $\mathrm{K}$ is the homologous temperature) [1]. It is an imperative issue, which could lead to failure of engineering materials that are under stress and exposed to high-temperature environments. Compressive creep tests are a convenient method for investigating high-temperature deformation, especially for strong and brittle refractory materials such as ceramics [2-4]. Creep generally includes three different stages: the primary, secondary and tertiary stage (Figure 1). The primary and tertiary are the initial and final stages, in which there is a transient strain rate that decelerates to a steady rate or accelerates up to failure by rupture, respectively. Meanwhile, during the second stage, termed steady-state creep the strain rate is constant (or nearly constant). The creep rate in this stage is used to evaluate high-temperature deformation and creep behavior of materials.

Measuring steady-state creep rate is important for prediction of the service lifetime for structural components, as well as understanding the micromechanics and metallurgical aspects of high-temperature deformation. Accurate strain rate measurements make it possible to determine creep parameters and identify the operating deformation mechanisms $[5,6]$. Creep rate generally depends on either external conditions, such as temperature and applied stress, or material properties, such as grain size and presence of precipitates or dopants.

Creep strain rate is most sensitive to the temperature and applied stress and can be described by an Arrhenius exponential and power-law dependency, respectively. The basic power-law creep equation is generally presented as:

$$
\dot{\varepsilon}=A \sigma^{n} \exp \left(-\frac{Q}{R T}\right)
$$


where $A$ is a constant, $\sigma$ is the applied stress, $n$ is the stress exponent, $Q$ is the apparent activation energy, $R$ is the gas constant and $T$ is the temperature. The experimental creep rates can then be analyzed according to their dependency on stress and temperature which allows to determine values of $Q$ and $n$.

$$
\ln \dot{\varepsilon}=\ln A+n \ln \sigma-\frac{Q}{R T}
$$

The creep apparent activation energy $(Q)$, which is inherent to the material, reflects the diffusion processes taking place at elevated temperatures and determines the creep temperature dependence. Diffusion also acts as an accommodating process to grain boundary sliding and dislocation creep mechanisms at lower temperatures [6,7]. The stress exponent $(n)$ reflects the sensitivity to the applied stress and creep dependence on the load. According to Equation (2), $Q$ and $n$ can be determined by either measuring creep at different temperatures under same applied load, or at the same temperature under different applied loads, respectively. A proper creep test setup must allow precise gauging of the temperature and stress applied to the sample with accurate measurements of the axial displacement [8].

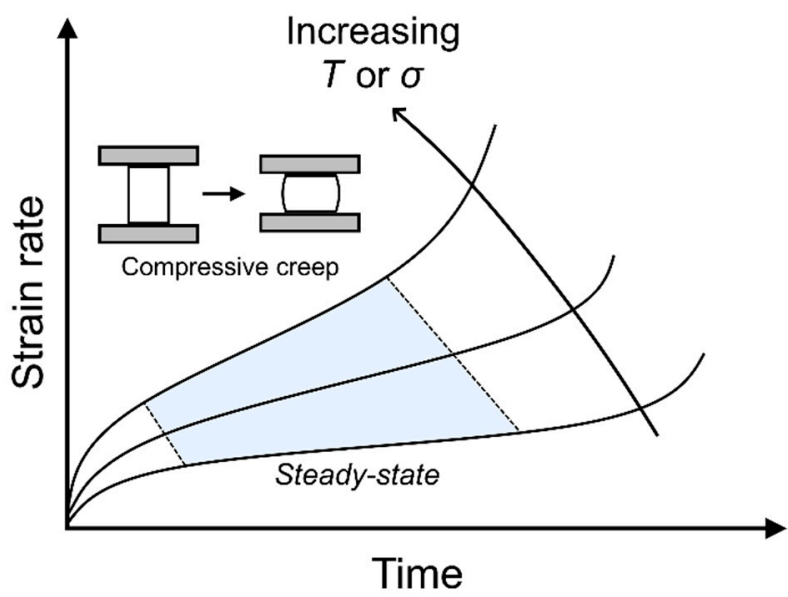

Figure 1. Schematic illustration of creep curves; strain rate increases with temperature or applied stress.

Spark plasma sintering (SPS) is an advanced pressure-assisted sintering technique, which utilizes an electric current for heat generation within conductive tooling and powder compacts $[9,10]$. This combination makes it possible to achieve excellent sintering capabilities of many metallic, ceramic and composite materials [11]. To track the densification progress, the SPS apparatus is equipped with a strain gauge and built in LVDT. It records the punch displacement every second with an accuracy of $\sim 1 \mu \mathrm{m}$ (depending on the SPS system). Consequently, the SPS apparatus encompasses all the necessary components (including temperature and load control) to perform compressive creep tests. Therefore, it was suggested that the SPS apparatus could be used as an accurate creep testing tool [12]. Such capabilities have already been demonstrated for both ceramics [12,13] and metals [14,15]. It is worthy to note that SPS creep test results have already shown good agreement with previously reported data obtained by conventional testing methods for the same materials at similar temperature/pressure ranges [12-15]. Moreover, it has been proposed that the SPS apparatus' ability to apply an electric current to the sample makes it possible to investigate to some extent electro-plastic effects in conductive materials during high temperature deformation [14,15]. This is particularly important for SPS, because it could also be directly connected to the enhanced sintering behavior of conducting materials [16,17].

In the present study, we describe in detail the use of an SPS apparatus for creep investigation of metals and ceramics, highlight the advantages and disadvantages of this method, and provide prominent experimental examples of creep tests performed by an SPS apparatus applied as a creep testing device. 


\section{Test Setup and Procedure}

\subsection{SPS Apparatus Technical Details}

The SPS apparatus requires practically no modification to serve as a creep testing device in compliance with ASTM technical standards [18]. The following description is based on an FCT system SPS (FCT Systeme GmbH, Rauenstein, Germany), but would generally be the same for other SPS machines from other manufacturers. The system allows to easily set the testing parameters (i.e., load, temperature) and track them continuously in $1 \mathrm{~s}$ intervals, along with many other parameters derived from them (e.g., punch displacement, current, voltage). The specifications of the SPS apparatus used in this study are given in Table 1.

Table 1. Lab-scale HP-D 10 FCT system SPS apparatus specifications relevant to creep testing.

\begin{tabular}{cccccc}
\hline $\begin{array}{c}\text { Temperature } \\
\text { Range, }{ }^{\circ} \mathbf{C}\end{array}$ & Pressing Force, $\mathbf{k N}$ & $\begin{array}{c}\text { Displacement } \\
\text { Resolution, } \mathbf{m m}\end{array}$ & $\begin{array}{c}\text { Programmable } \\
\text { Test Segments }\end{array}$ & $\begin{array}{c}\text { Electric Current } \\
\text { Applied to Sample }\end{array}$ & $\begin{array}{c}\text { Chamber } \\
\text { Atmosphere }\end{array}$ \\
\hline Up to 2400 & $\begin{array}{c}3-100 \text { (stress depends on } \\
\text { sample cross-section) }\end{array}$ & 0.001 & Yes & $\begin{array}{c}\text { Possible for conductive } \\
\text { samples }\end{array}$ & $\begin{array}{c}\text { Vacuum } \\
\left(10^{-2} \text { mbar }\right) \text { with } \\
\text { argon flow }\end{array}$ \\
\hline
\end{tabular}

To perform a creep test, a columnar sample is set at the center between the punches. To ensure that the sample is placed in an unconstrained manner, the initial and final sample dimensions should be considered prior to the test. The relative punch displacement (RPD) is monitored with an accuracy of $\sim 1 \mu \mathrm{m}$ for an HP-D10 FCT System (this may vary for other machines). The measured RPD can be converted to strain, simply by dividing it by the initial sample height while taking in account the thermal expansion of the material. The corresponding creep rate can then be determined from the slope or derivative of the strain curve [12,14].

\subsection{Test Configurations and Temperature Considerations}

The temperature in the SPS apparatus is typically measured using the built-in system pyrometer or thermocouples. For the best accuracy during creep tests, it was suggested to place a thermocouple (C, K or S type for our system) in direct contact with the sample surface (see Figure 2). Temperature distribution in SPS is a known issue which also depends on the tooling configuration [19,20]. If there is only resistive heating of the sample during creep tests of conducting materials (i.e., tooling without a surrounding die as was used in our previous studies $[14,15])$ the temperature deviations may be relatively large due to significant heat loss from the sample surface. To mitigate this, it is suggested in the present study to apply an electric current while using the graphite die, like the configuration discussed in [21]. The minor disadvantage in this case is that the electric current value applied by the SPS apparatus splits between the die and sample. The actual current applied to the sample $\left(\mathrm{I}_{\mathrm{S}}\right)$ can then only be estimated according to the relative electrical resistance of the tooling and the sample according to the Kirchhoff's law. Thus, the different heating configurations for SPS apparatus creep tests are as depicted in Figure 2. In which conductive materials can be resistively heated by passage of an electric current as well as by heat convection and radiation from the graphite punches and die, respectively. The electric current can be avoided by separating the sample from the graphite by the means of a ceramic insulator, such as alumina. When tests are conducted at relatively high temperatures a graphite felt should be placed around the die to further mitigate heat dissipation.

To estimate possible temperature distributions in samples tested with different tooling configuration, a special set of temperature measurements was conducted. The measurements were performed on a cylindrical copper sample with several $1.5 \mathrm{~mm}$ holes drilled $6 \mathrm{~mm}$ deep into the center, top and bottom (Figure 3). Using two thermocouples simultaneously, multiple temperature measurements (in the 450-550 ${ }^{\circ} \mathrm{C}$ temperature range) were performed. Each measurement was taken when the temperature was stabilized. The results for both tooling configurations are summarized in Table 2. The temperature was defined according to the thermocouple located on the sample surface. When testing the difference 
between the center and top/bottom regions the temperature was defined according to the thermocouple located in the center of the sample.
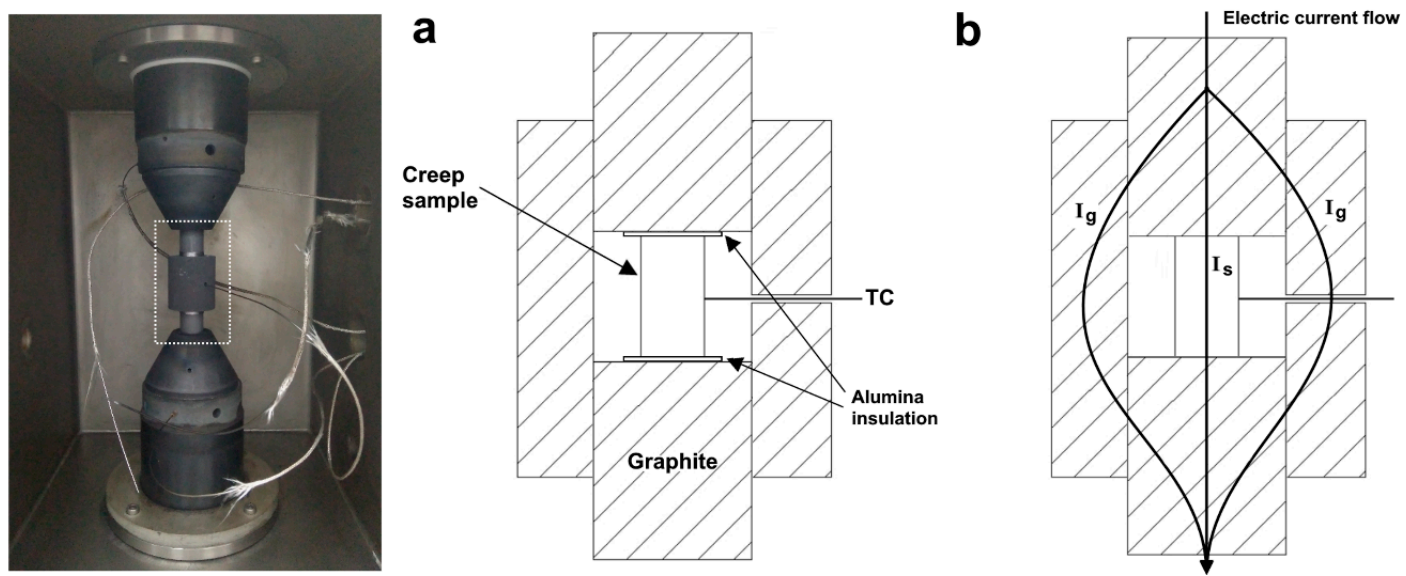

Figure 2. Schematics and images of configurations creep testing (a) without and (b) with electric current applied to the sample. The electric current flow is portrayed schematically.

The tests revealed the presence of a temperature gradient within the sample. In the case of a sample insulated from the electric current (Figure 2a), the radial temperature difference, between the surface and center is about $\sim 15{ }^{\circ} \mathrm{C}$. This difference in temperature would exists in any conventional creep test apparatus, since the sample is heated from the outside. As for the case with the electric current, the measurements showed a larger difference of roughly $\sim 20-30{ }^{\circ} \mathrm{C}$ between the center and surface. However, we believe that these values should be taken with a grain of salt. The temperature measured in the center may be inaccurate due to higher current density developing around the hole. Even a small addition of current would cause significant extra localized heating around the thermocouple, making these measurements erroneous. In fact, considering the rate of heat loss from the surface, we expect that the real temperature gradient is roughly the same as was observed for the insulated sample (or even lower since the whole sample is heated by the current), but in the reverse direction. Additionally, there is also a difference between the top and the bottom of the sample This difference can be attributed to the SPS apparatus design in which the upper punch is the positive electrode and usually hotter. As shown by Sweidan et al. [21], approaches can be taken to minimize temperature deviations and achieve more accurate testing.

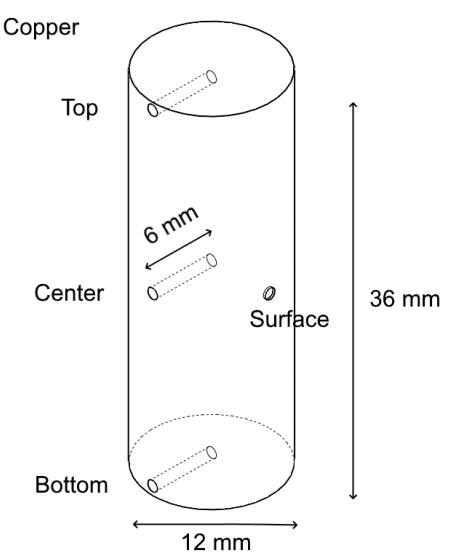

Figure 3. Schematic illustration of copper sample and the holes used for temperature measurements.

The uncertainty of the temperature measurements may be problematic to directly compare results of creep tests with and without an electric current and to discuss the effect of electro-plasticity. 
Furthermore, it should be considered that for such creep tests at elevated temperatures joule heating effects also contribute to deformation and stress relaxation and cannot be easily de-coupled from the electro-plastic effect [22]. This issue will be further considered in the next section.

Table 2. Temperatures measured at various regions of copper sample for the different testing configurations with or without passage of an electric current.

\begin{tabular}{ccccc}
\hline Test Configuration & $\begin{array}{c}\text { Temperature at the } \\
\text { Surface, }{ }^{\circ} \mathbf{C}\end{array}$ & $\begin{array}{c}\text { Temperature at the } \\
\text { Center, }{ }^{\circ} \mathbf{C}\end{array}$ & $\begin{array}{c}\text { Temperature at the } \\
\text { Top, }{ }^{\circ} \mathbf{C}\end{array}$ & $\begin{array}{c}\text { Temperature at the } \\
\text { Bottom, }{ }^{\circ} \mathbf{C}\end{array}$ \\
\hline With electric & 450 & $473^{*}$ & $515^{*}$ & $501^{*}$ \\
current & 500 & $524^{*}$ & & \\
\hline Insulated from the & 550 & $579 *$ & \\
electric current & 550 & 438 & \\
\end{tabular}

* Suspected to be inaccurate due to high current density causing a temperature rise around the thermocouple locations.

\subsection{Creep Testing Procedure}

The creep test itself is performed in a relatively simple manner, by setting the designated temperature and load (pressure is calculated according to sample cross-section) and tracking RPD. The test can be conducted under constant temperature or load, but also with various pressure or temperature steps [15], to obtain multiple creep rate measurements from a single sample. An example for a testing procedure of alumina (at $1250{ }^{\circ} \mathrm{C}$ under $80 \mathrm{MPa}$ ), including all relevant experimental data necessary for creep evaluation, is presented in Figure 4. The heating stage I (Figure 4), is conducted prior to the creep test, while a minimal or designated test force is applied. At this stage, the negative RPD indicates the thermal expansion of the graphite tooling system and stainless-steel pistons. In segments II-III (Figure 4), the recorded displacement reflects only sample deformation after a mechanical and thermal equilibrium have been reached. In segment II there is a rapid decrease in the strain rate, while in segment III the strain rate is practically constant. Thus, segments II-III are considered primary and steady-state creep, respectively. It should be noted that the steady-state mentioned above (segment III) is sometimes a quasi-steady-state, due to the continuous reduction of true stress during creep (Figure 4) as well as concurrent grain growth $[23,24]$. This would be more of an issue at high strain rates under testing conditions of relatively high temperatures or applied stress [12].

Nevertheless, using an SPS apparatus for creep tests has several technical limitations. A minimal load of $3 \mathrm{kN}$ must be applied during the test in order to receive displacement recording. This limits the sample size and determines the minimal applied stress. Furthermore, the SPS system cannot be set for a certain stress or constant strain rate and thus the accurate measurement of high-temperature compressive strength cannot be performed. Since the SPS apparatus typically only allows to apply a constant load, the actual stress on the sample continuously decreases during the test as the sample cross-section expands with increasing strain (Figure 5). This issue is treated by calculating the true strain (for any given moment) [25].

$$
\varepsilon_{t}(t)=\ln \frac{l_{t}}{l_{0}}
$$

where $\varepsilon_{t}$ is the true strain, $l_{t}$ is the current specimen height at a given point in time and $l_{0}$ is the initial specimen height. Considering volume conservation (before excessive cavitation at final stages of creep), the true stress $\sigma_{t}$ can then be calculated.

$$
\sigma_{t}=\frac{F}{a_{0}^{2}}\left[\exp \left(\varepsilon_{t}\right)\right]
$$

where $F$ is the applied load and $a_{0}^{2}$ is the initial sample cross-section area. 
Thus, the strain rate during compressive creep tests can be summarized as the following equation.

$$
\dot{\varepsilon}=A\left(\frac{F}{a_{0}^{2}}\left[\exp \left(\varepsilon_{t}\right)\right]\right)^{n} \exp \left(\frac{-Q}{R T}\right)
$$

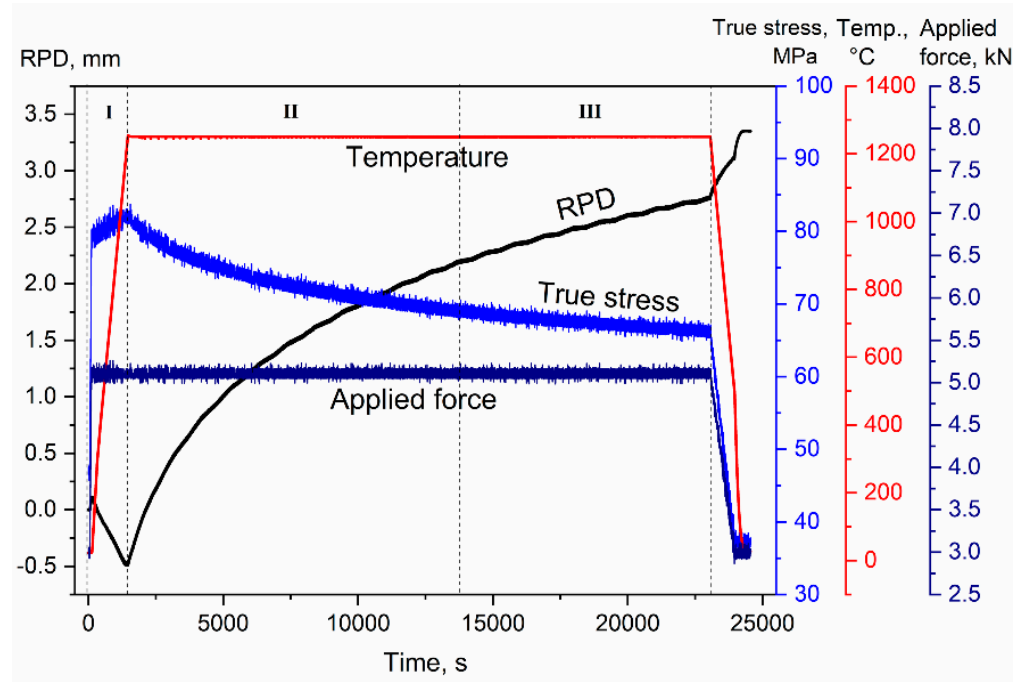

Figure 4. Creep test variables recorded by the SPS system (true stress is calculated). The different test stages (segments I, II and III) related to conducting a creep test are depicted [12]. Reproduced with permission of Elsevier.

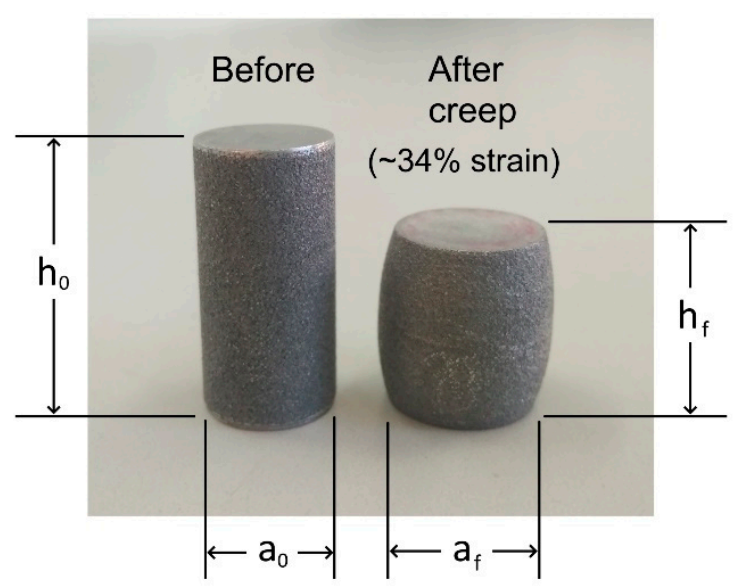

Figure 5. Example of $\mathrm{AlSi}_{10} \mathrm{Mg}$ samples before and after creep test $(\sim 34 \%$ strain $)$ at $225^{\circ} \mathrm{C}$ under an initial applied pressure of $130 \mathrm{MPa}$.

\section{Results and Discussion}

\subsection{Creep Testing of Metals}

As discussed in the previous section, metals (and other conductive materials) can be tested by heating generated from the graphite tooling while insulated from the punches or including resistive heating within the sample by allowing passage of the electric current through the sample. In our previous study on copper [14], it was shown that SPS-measured creep rates without the current agree quite well with results of conventional tensile creep tests that have been performed on copper under at the same temperature range $\left(400-600^{\circ} \mathrm{C}\right)$. The slope against the reciprocal of temperature is similar, which means that the creep apparent activation energy $Q$ is the same. In this case, $Q$ was equal to about $110 \mathrm{~kJ} / \mathrm{mol}$, which corresponds to vacancy migration (dislocation motion in vacancy saturation) [26]. 
This validated the SPS apparatus as an accurate creep testing tool. Nevertheless, for the case with applied electric current we used only resistive heating without surrounding die and the obtained results regarding electro-plastic effect may be questionable.

Therefore, in the present study, we performed additional creep experiments on similar copper samples with a surrounding die, which allows to lower the temperature gradient. These isothermal creep tests were conducted with load increments of 30, 40 and $50 \mathrm{~N}$, while maintaining a constant temperature of $500{ }^{\circ} \mathrm{C}$. This makes it possible to investigate the stress dependence and determine the stress exponent $n$. Each of these tests was performed in both possible configurations, with and without an electric current. The obtained creep curves are presented in Figure $6 \mathrm{a}$, and the calculated creep rates are presented as a function of stress in Figure $6 \mathrm{~b}$. It was found that the value of $n$ without the current was close to 4 which agrees with the known values for stress exponent of copper at relatively low stress ( $<100 \mathrm{MPa}$ ) and intermediate homologues temperatures [27]. While the value with the applied current was significantly lower, at around 2.3 (which is very low for copper). It has to be pointed out that stress exponent does not depend a relatively small temperature difference. See for instance a comparison with reported data for copper creep (tensile) at various temperatures (Figure 6c). Thus, the considerable difference of in the stress exponent could only be attributed to some electro-plastic effect which may affect the creep mechanism. Nevertheless, it is quite difficult to de-couple between the additional heating and electro-plastic effect, but the latter clearly has a contribution to susceptibility to creep $[28,29]$. Such results help to explain enhanced densification during SPS of conducting materials under influence of an electric current [16]. It perhaps may be possible to gain a deeper understanding on the matter by performing creep tests with different electric currents by altering the SPS tooling [30].
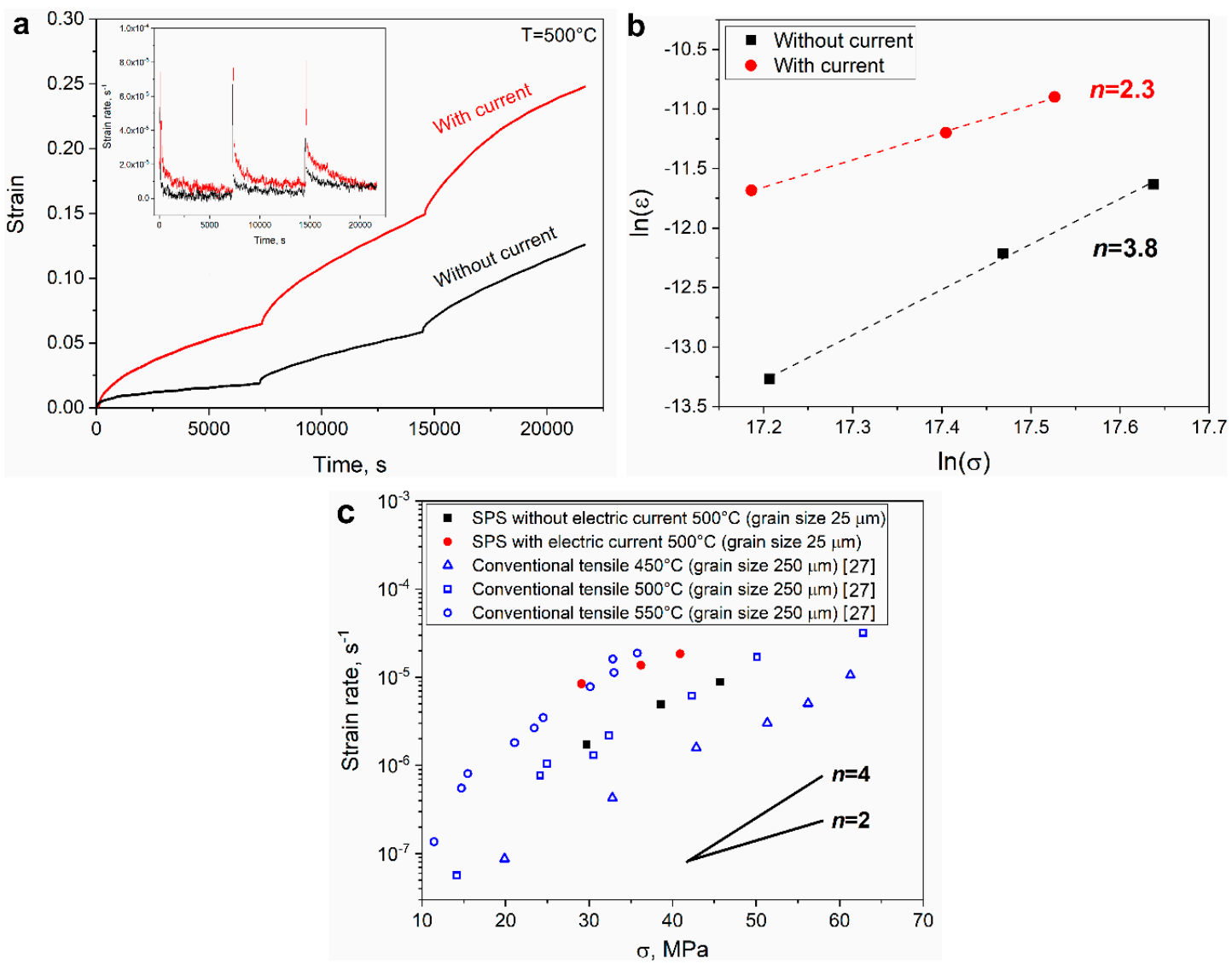

Figure 6. (a) Example of copper creep test at $500{ }^{\circ} \mathrm{C}$ with three load steps with and without an applied current, the corresponding strain rate in the insert; (b) the creep rates as a function of stress (natural $\log$ ) with the slope value $n$ indicated and (c) as a function of stress compared with other reported results [27] for tensile creep of copper at various temperatures (notice the different grain size). 


\subsection{Creep Testing of Ceramics}

In the case of insulating ceramics, a configuration involving the graphite die must be used (Figure 2). However, it should be taken into account that some ceramics are still conductive, such as $\mathrm{ZrN}$, and would involve an effect of electric current within the sample [17]. Also, under strong electric fields there may also be field effects in ceramics that can influence the creep behavior [22]. SPS was applied for a creep study of polycrystalline $\mathrm{MgAl}_{2} \mathrm{O}_{4}$ (for the first time) to clarify the deformation mechanisms at high temperature under relatively high stress [13]. For instance, it was found that the apparent activation energy decreases with increased applied stress. To further validate the creep measurements obtained by an SPS apparatus, it was used to examine alumina, perhaps the most widely researched ceramic material. Alumina single stage creep curves from a previous study [12], performed at various temperatures (in the range of $1125-1250^{\circ} \mathrm{C}$ ) and under an applied stress of 100 $\mathrm{MPa}$, are presented in Figure 7a. Corresponding strain rates (according to the derivative over time) are presented in Figure $7 \mathrm{~b}$. The dramatic effect of the temperature on the total strain and strain rate (slope) can be easily observed. Furthermore, alumina creep rate values obtained at $1200^{\circ} \mathrm{C}$ under varying loads are presented as a function of stress, alongside values from a study conducted in compression by Bernard-granger et al. [31] (Figure 7c). Both studies were performed on alumina with a similar fine grain size ( 0.5 and $0.42 \mu \mathrm{m}$, respectively). Here, as well, there is a good agreement between creep measurements by SPS and data reported in literature. The slope reflects the sensitivity to the applied stress and corresponds to a stress exponent $n$ of about 1.8 which is close to 2 and established for fine-grained alumina [12,32].
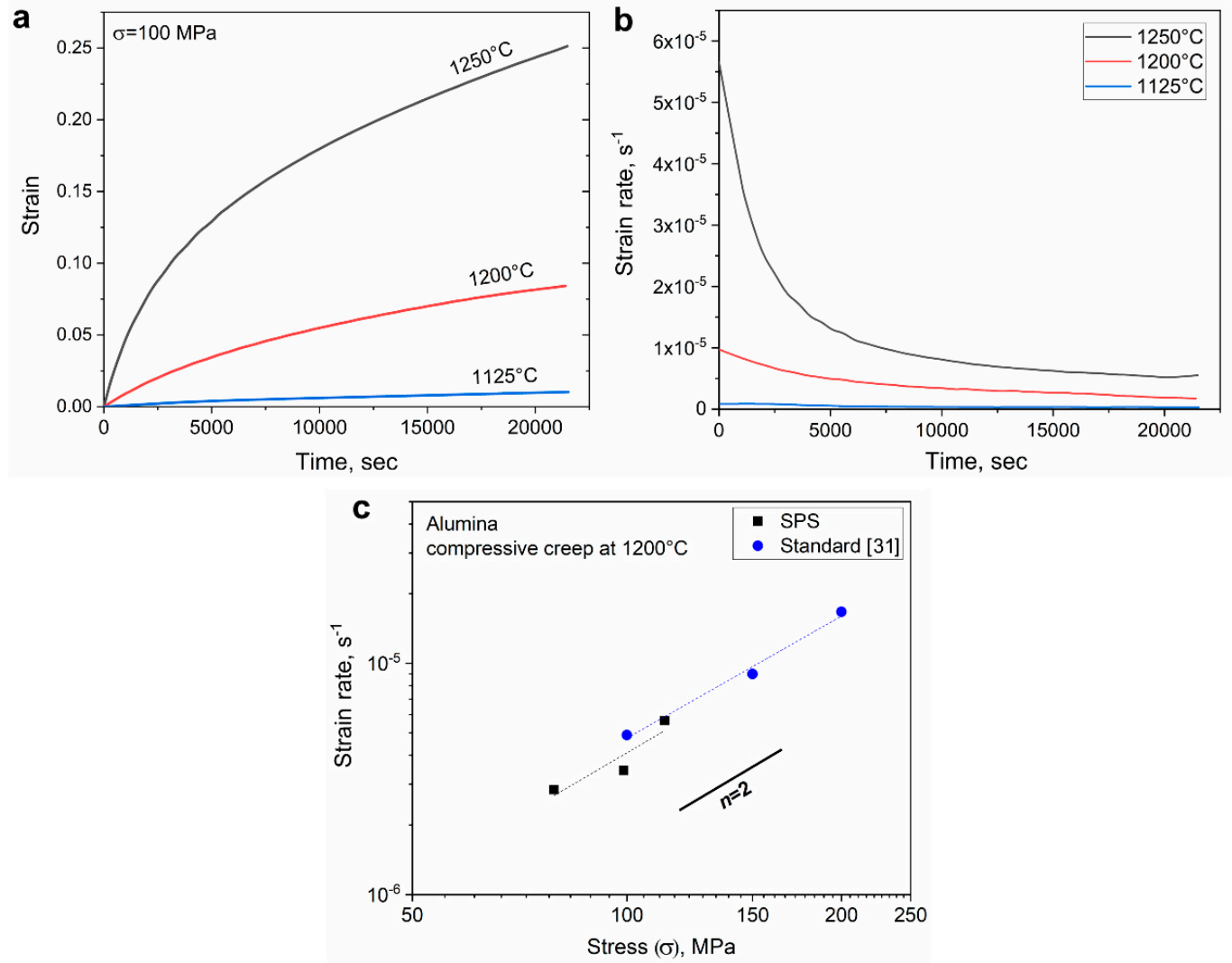

Figure 7. (a) Example of alumina creep tests strain under an applied stress of $100 \mathrm{MPa}$ at the $1125-1250^{\circ} \mathrm{C}$ temperature range and (b) corresponding strain rates; (c) comparison of creep rates (at $1200{ }^{\circ} \mathrm{C}$ and varying stress) measured for alumina by an SPS apparatus in compression (black squares) and conventional compression testing equipment [31] (blue circles). 


\subsection{High-Pressure Creep Tests}

In some cases, such as for Ni-based superalloys, there is a lot of interest in creep properties under high-stress conditions [33-35]. Typically, it is difficult to examine high-temperature deformation under high applied stress. However, one of the advantages of the SPS apparatus as a creep testing device is that it can allow tests under stresses of hundreds of $\mathrm{MPa}$, using proper high-pressure tooling such as $\mathrm{SiC}$ punches [12]. The materials that can be investigated will depend on properties of the high-pressure tooling. For instance, $\mathrm{SiC}$ has significantly higher resistance to creep [36] compared to oxide ceramics and can be applied for such tests under high pressure. This was demonstrated for alumina, which was tested under an applied pressure of $400 \mathrm{MPa}$ (sample dimensions $5 \times 5 \times 10 \mathrm{~mm}$ ), as presented in Figure 8. These types of tests can clarify creep mechanisms and unique mechanical behavior of materials subjected to a combination of high temperature and stress.
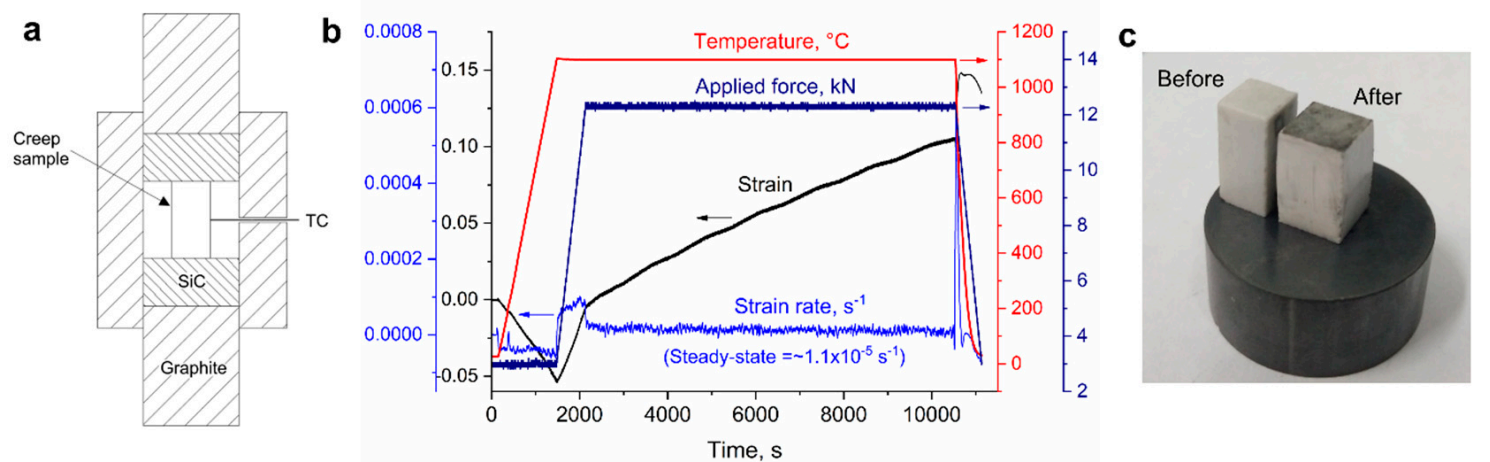

Figure 8. (a) Schematic illustration of hybrid SiC-graphite tooling for high-pressure experiments; (b) an example for a high-pressure creep test of alumina (sample size $5 \times 5 \times 10 \mathrm{~mm}$, initial applied stress $400 \mathrm{MPa}) ;(\mathbf{c})$ appearance of samples before and after the high-stress creep test.

\section{Conclusions}

An SPS apparatus can be used for studying high temperature mechanical properties, particularly compressive creep of metals and ceramics. In this apparatus, a wide range of temperatures and pressures can be applied, and all the necessary data for creep tests can be easily acquired. However, the SPS apparatus, as a tool for mechanical testing, has some technical limitations, including the mandatory minimal load of $3 \mathrm{kN}$, the lack of a possibility for tensile testing, and the fact that only a constant load regime can be applied. Nevertheless, different tooling configurations may be used so that conductive materials can be tested with or without an applied electric current. This affects the different temperature gradients which exist in the sample, especially when an electric current is applied. Nevertheless, the current that the SPS apparatus utilizes can make it possible to investigate electro-plastic effects to some extent. Furthermore, creep tests under relatively high applied stress (in the range of few hundreds MPa) can also be realized by the SPS apparatus. Several creep test results obtained by an SPS apparatus were presented, and experimental creep results for metals (copper) and ceramics (alumina) proved the accuracy of this device for creep testing of engineering materials. Thus, the SPS apparatus can serve as a relatively simple and convenient method for a wide range of creep testing of both metals and ceramics.

Author Contributions: This study was conceptualized by B.R. and N.F.; experiments were performed by S.K.; data curation by S.K. and B.R.; data analysis by B.R. and S.K.; writing by B.R.; supervised by N.F. All authors have read and agreed to the published version of the manuscript.

Funding: This research received no external funding.

Conflicts of Interest: The authors declare no conflict of interest. 


\section{References}

1. Kassner, M.E. Fundamentals of Creep in Metals and Alloys, 3rd ed.; Butterworth Heinemann imprint of Elsevier: Waltham, MA, USA, 2015.

2. Carroll, D.F.; Wiederhorn, S.M. High temperature creep testing of ceramics. Int. J. High Technol. Ceram. 1988, 4, 227-241. [CrossRef]

3. Yoon, K.J.; Wiederhorn, S.M.; Luecke, W.E. Comparison of tensile and compressive creep behavior in silicon nitride. J. Am. Ceram. Soc. 2004, 83, 2017-2022. [CrossRef]

4. Longhin, M.E.; Shelleman, D.L.; Hellmann, J.R. A methodology for the accurate measurement of uniaxial compressive creep of refractory ceramics. meas. J. Int. Meas. Confed. 2017, 111, 69-83. [CrossRef]

5. Cannon, W.R.; Langdon, T.G. Review creep of ceramics-Part 1 mechanical characteristics. J. Mater. Sci. 1983, 18, 1-50.

6. Langdon, T.G. Identifying creep mechanisms in plastic flow. Z. Für Met. 2005, 96, 522-531. [CrossRef]

7. Raj, R.; Ashby, M.F. On grain boundary sliding and diffusional creep. Metall. Trans. 1971, 2, $1113-1127$. [CrossRef]

8. Gibeling, J.C. ASM Handbook Volume 8: Mechanical Testing and Evaluation; ASM International: Novelty, $\mathrm{OH}$, USA, 2000.

9. Guillon, O.; Gonzalez-Julian, J.; Dargatz, B.; Kessel, T.; Schierning, G.; Räthel, J.; Herrmann, M. Field-assisted sintering technology/spark plasma sintering: mechanisms, materials, and technology developments. Adv. Eng. Mater. 2014, 16, 830-849. [CrossRef]

10. Cavaliere, P. Spark Plasma Sintering of Materials; Springer Nature: Cham, Switzerland, 2019.

11. Orru, R.; Licheri, R.; Locci, A.M.; Cincotti, A.; Cao, G. Consolidation/Synthesis of materials by electric current activated/assisted sintering. Mater. Sci. Eng. R Rep. 2009, 63, 127-287. [CrossRef]

12. Ratzker, B.; Sokol, M.; Kalabukhov, S.; Frage, N. Using a spark plasma sintering apparatus as a tool in a compressive creep study of fine-grained alumina. Ceram. Int. 2017, 43, 9369-9376. [CrossRef]

13. Ratzker, B.; Sokol, M.; Kalabukhov, S.; Frage, N. Creep of polycrystalline magnesium aluminate spinel studied by an SPS apparatus. Materials 2016, 9, 493. [CrossRef]

14. Ratzker, B.; Sokol, M.; Kalabukhov, S.; Frage, N. compression creep of copper under electric current studied by a spark plasma sintering (SPS) apparatus. Mater. Sci. Eng. A 2018, 712, 424-429. [CrossRef]

15. Uzan, N.E.; Ratzker, B.; Landau, P.; Kalabukhov, S.; Frage, N. Compressive creep of $\mathrm{AlSi}_{10} \mathrm{Mg}$ parts produced by selective laser melting additive manufacturing technology. Addit. Manuf. 2019, 29, 100788. [CrossRef]

16. Li, W.; Olevsky, E.A.; McKittrick, J.; Maximenko, A.L.; German, R.M. Densification mechanisms of spark plasma sintering: Multi-step pressure dilatometry. J. Mater. Sci. 2012, 47, 7036-7046. [CrossRef]

17. Lee, G.; Olevsky, E.A.; Manière, C.; Maximenko, A.; Izhvanov, O.; Back, C.; McKittrick, J. Effect of electric current on densification behavior of conductive ceramic powders consolidated by spark plasma sintering. Acta Mater. 2018, 144, 524-533. [CrossRef]

18. E209-18 Standard Practice for Compression Tests of Metallic Materials at Elevated Temperatures with Conventional or Rapid Heating Rates and Strain Rates; ASTM E209-18; ASTM International: West Conshohocken, PA, USA, 2018.

19. Achenani, Y.; Saâdaoui, M.; Cheddadi, A.; Fantozzi, G. Finite element analysis of the temperature uncertainty during spark plasma sintering: Influence of the experimental procedure. Ceram. Int. 2017, 43, 15281-15287. [CrossRef]

20. Manière, C.; Durand, L.; Brisson, E.; Desplats, H.; Carré, P.; Rogeon, P.; Estournès, C. Contact resistances in spark plasma sintering: From in-situ and ex-situ determinations to an extended model for the scale up of the process. J. Eur. Ceram. Soc. 2017, 37, 1593-1605. [CrossRef]

21. Sweidan, F.B.; Kim, D.H.; Ryu, H.J. Minimization of the sample temperature deviation and the effect of current during high-temperature compressive creep testing by the spark plasma sintering apparatus. Materialia 2020, 9, 100550. [CrossRef]

22. Conrad, H. Thermally activated plastic flow of metals and ceramics with an electric field or current. Mater. Sci. Eng. A. 2002, 322, 100-107. [CrossRef]

23. Chokshi, A.H.; Porter, J.R. Analysis of concurrent grain growth during creep of polycrystalline alumina. J. Am. Ceram. Soc. 1986, 37, 36-37. [CrossRef]

24. Xue, L.A.; Chen, I. Deformation and grain growth of low-temperature-sintered high-purity alumina. J. Am. Ceram. Soc. 1990, 73, 3518-3521. [CrossRef] 
25. Venkatachari, K.R.; Raj, R. Superplastic flow in fine-grained alumina. J. Am. Ceram. Soc. 1986, 38, $135-138$. [CrossRef]

26. Feltham, P.; Meakin, J.D. Creep in face-centred cubic metals with special reference to copper. Acta Metall. 1959, 7, 614-627. [CrossRef]

27. Raj, S.V.; Langdon, T.G. Creep behavior of copper at intermediate temperatures-I. Mechanical characteristics. Acta Metall. 1989, 37, 843-852. [CrossRef]

28. Klypin, A.A. Plastic deformation of metals in the presence of electric influences. Strength Mater. 1975, 7, 810-815. [CrossRef]

29. Cao, W.D.; Conrad, H. Effect of Stacking Fault Energy and Temperature on the Electroplastic Effect in FCC Metals. In Micromechanics of Advanced Materials: A Symposium in Honor of Professor James C.M. Li's 70th Birthday; Minerals, Metals \& Materials Society: Warrendale, PA, USA, 1995.

30. Giuntini, D.; Olevsky, E.A.; Garcia-cardona, C.; Maximenko, A.L.; Yurlova, M.S.; Haines, C.D.; Martin, D.G.; Kapoor, D. Localized overheating phenomena and optimization of spark-plasma sintering tooling design. Materials 2013, 6, 2612-2632. [CrossRef]

31. Bernard-Granger, G.; Guizard, C.; Duclos, R. Compressive creep behavior in air of a slightly porous as-sintered polycrystalline $\alpha$-alumina material. J. Mater. Sci. 2007, 42, 2807-2819. [CrossRef]

32. Ruano, O.A.; Wadsworth, J.; Sherby, O.D. Deformation of fine-grained alumina by grain boundary sliding accommodated by slip. Acta Mater. 2003, 51, 3617-3634. [CrossRef]

33. $\mathrm{Xu}, \mathrm{Q}$;; Hayhurst, D.R. The evaluation of high-stress creep ductility for 316 stainless steel at $550{ }^{\circ} \mathrm{C}$ by extrapolation of constitutive equations derived for lower stress levels. Int. J. Press. Vessel. Pip. 2003, 80, 689-694. [CrossRef]

34. Izuno, H.; Yokokawa, T.; Harada, H. An applicability of a creep constitutive equation for Ni-base superalloys on low temperature high stress condition. J. Jpn. Inst. Met. 2006, 70, 674-677. [CrossRef]

35. Wu, X.; Dlouhy, A.; Eggeler, Y.M.; Spiecker, E.; Kostka, A.; Somsen, C.; Eggeler, G. On the nucleation of planar faults during low temperature and high stress creep of single crystal Ni-base superalloys. Acta Mater. 2018, 144, 642-655. [CrossRef]

36. Munro, R.G. Material properties of a sinterd $\alpha$-SiC. J. Phys. Chem. Ref. Data. 1997, 26, 1195-1203. [CrossRef]

(C) 2020 by the authors. Licensee MDPI, Basel, Switzerland. This article is an open access article distributed under the terms and conditions of the Creative Commons Attribution (CC BY) license (http://creativecommons.org/licenses/by/4.0/). 